\title{
Crystallization in Binary Blends of Polytetrafluoroethylene with Perfluorinated Tetrafluoroethylene Copolymer
}

\author{
Masahiro Endo, ${ }^{\dagger}$ Aki OHNISHI, Shoichi KuTsumizu, \\ Tetsuo SHIMIZU, ${ }^{*}$ and Shinichi YANO ${ }^{\dagger \dagger}{ }^{\dagger \dagger \dagger}$ \\ Department of Chemistry, Faculty of Engineering, Gifu University, Yanagido, Gifu 501-1193, Japan \\ *Daikin Industries Ltd., Nishihitotsuya, Settsu 566-8585, Japan
}

(Received February 24, 2004; Accepted June 14, 2004; Published September 15, 2004)

\begin{abstract}
Miscibility and crystallization were studied for two binary blends of polytetrafluoroethylene (PTFE) with poly(tetrafluoroethylene-co- $10 \mathrm{~mol} \%$ hexafluoropropylene) (FEP) and poly(tetrafluoroethylene-co-2 mol $\%$ perfluoropropylvinyl ether) (PFA), using DSC and X-Ray diffractometry. In FEP/PTFE blends, FEP and PTFE components were separately crystallized to form their own crystallites, while in PFA/PTFE blends, PFA and PTFE components were cocrystallized to form PTFE-type crystallites incorporating tetrafluoroethylene segments of PFA and PTFE. The crystallization behavior in both blends is discussed in terms of chemical structure, molecular weight, crystallization rate, blending method (how the two components are blended) and comonomer concentration.

[DOI 10.1295/polymj.36.716]

KEY WORDS Polytetrafluoroethylene / Poly(tetrafluoroethylene-co-10 mol \% hexafluoropropylene) / Poly(tetrafluoroethylene-co-2 mol \% perfluoropropylvinyl ether) / Blends / Crystallization /
\end{abstract}

Polytetrafluoroethylene (PTFE) is a polymer with good thermal stability up to $720 \mathrm{~K}$, excellent chemical resistance to many solvents, low surface energy, and good electric insulation. ${ }^{1}$ However, PTFE used industrially is generally required to have high molecular weight (for example, Teflon 3170 has an average number molecular weight, $M_{\mathrm{n}}$, of about $3.6 \times 10^{5}$ ) enough to avoid excess crystallization, but the high molecular weight results in the high melt viscosity, and hence special processing technology such as powder sintering and paste extrusion is required to reform PTFE powders, for example, into sheets. To overcome the above undesirable properties of PTFE, fluorinated copolymers of tetrafluoroethylene (TFE), such as poly(tetrafluoroethylene-co-hexafluoropropylene) (FEP) and poly(tetrafluoroethylene-co-perfluoroalkylvinyl ether) (PFAVE), have been developed. These copolymers are semicrystalline polymers and their melt viscosities are in general lowered by the introduction of comonomer, compared with those of PTFE, allowing their molding by usual melting extrusion and injection molding technologies.

Recently, scientific interest has been paid to miscibility and crystallization in binary polymer blends. ${ }^{2}$ In particular, it is important to clarify how and why miscibility and crystallization occur in semicrystalline polymer/semicrystalline polymer blends. Miscibility and crystallization behavior has been investigated for several binary blends of PTFE with perfluorinated

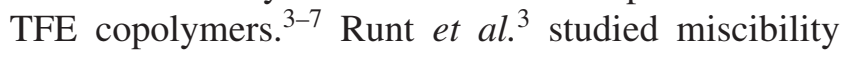
and crystallization for binary blends of PTFE (Teflon 3170 ) with poly(tetrafluoroethylene-co-perfluoropropylvinyl ether) (trade name Teflon PFA335, but simply called PFA in this paper), using dynamic mechanical (DM) spectroscopy and differential scanning calorimetry (DSC), where the perfluoropropylvinyl ether (PVE) content of the PFA was 1-2 mol \%. DM spectra as a function of temperature showed two peaks labeled $\alpha$ and $\beta$, which were related to reorientational motion of long segments above the glass transition temperature $\left(T_{\mathrm{g}}\right)$ and room temperature crystal-crystal transition, ${ }^{8}$ respectively. $\alpha$ relaxation existed as a single peak near $403 \mathrm{~K}$ for neat PTFE (100\% PTFE), and with increasing PFA content, moved to $\sim 373 \mathrm{~K}$ of neat PFA, which suggests that PTFE and PFA components mix in both amorphous region and molten state. The DSC curves for neat PTFE and neat PFA showed one melting and one crystallization peak in the heating and cooling processes, respectively. In PFA/PTFE blends, there were two melting and two crystallization peaks, originating from PTFE and PFA, except for a very rapid crystallization condition under which only one melting peak was observed. From these results, they concluded that in the PFA/PTFE blends, PTFE and PFA components mix in the amorphous region but crystallites are separately formed under most crys-

\footnotetext{
${ }^{\dagger}$ Permanent address: Kai Industries Co., Ltd., 1110 Oyana, Seki 501-3992, Japan

${ }^{\dagger}$ Permanent address: Emeritus Professor, Gifu University, R\&D Institute for Materials, 155 Hanado, Takaya, Konan 483-8046, Japan

${ }^{\dagger \dagger}$ To whom correspondence should be addressed (E-mail: yanos@cc.gifu-u.ac.jp).
} 
tallization conditions. Using DSC and X-Ray diffraction, Pucciariello et al. ${ }^{4,5}$ carefully investigated miscibility and crystallization behavior for binary blends of perfluorinated polymers, PFMVE2/PTFE, FEP/ PTFE, and FEP/PFMVEn blends, where PFMVEn means poly(tetrafluoroethylene-co-perfluoromethylvinyl ether) containing $n$ mol \% perfluoromethylvinyl ether (MVE) comonomer and in their studies PFMVEn of $n=2,4,6$ and $10 \mathrm{~mol} \%$ were used. The hexafluoropropylene (HFP) content in FEP was $1 \mathrm{~mol} \%$. In both PFMVE2/PTFE and FEP/PTFE blends, the two components were separately crystallized, showing no sign for cocrystallization. Crystallization behavior for FEP/PFMVEn blends is instructive. In FEP/PFMVE2 blends, cocrystallization occurred, regardless of the blending ratio, but two different crystallites separately formed in other FEP/ PFMVE $n$ blends with $n=4,6$, and 10 . The crystallization thus depends on the comonomer content. We reported the miscibility and crystallization of PFA/ PTFE blends, using DSC, DM and X-Ray diffractometry, ${ }^{6}$ where PVE content in PFA is about $2 \mathrm{~mol} \%$. PTFE and PFA components mixed and cocrystallized in the amorphous region. Clearly, some discrepancies are recognized on the crystallization in previous reports, especially for PFAVE/PTFE blends.

Perfluorinated copolymer/PTFE blends are important plastics, because they can be more easily meltprocessed than PTFE, and the blends retain mostly the unique properties of PTFE. It is, therefore, worthwhile to clarify the miscibility and crystallization behavior for perfluorinated TFE copolymer/PTFE blends. The present work clarifies the crystallization behavior for binary FEP (10 mol \% HFP)/PTFE and PFA ( $2 \mathrm{~mol} \%$ PVE)/PTFE blends, using DSC and $\mathrm{X}$-Ray diffraction. X-Ray diffraction patterns were from room temperature to $573 \mathrm{~K}$. Crystallization behavior in the perfluorinated TFE copolymer/PTFE blends is discussed with respect to chemical structure, molecular weight, comonomer content, blending method (how two components are blended) and thermodynamic factors.

\section{EXPERIMENTAL}

PTFE powders, FEP and PFA pellets were LDW40, NP20, and AP201 from Daikin Kogyo Ltd. (Japan). FEP and PFA are random copolymers, where HFP content in FEP was about $10 \mathrm{~mol} \%$ and PVE content in PFA about $2 \mathrm{~mol} \%$.

Average number molecular weight $\left(M_{\mathrm{n}}\right)$ was estimated $\sim 1 \times 10^{5}$ for PTFE, $\sim 2 \times 10^{5}$ for FEP, and $\sim 2 \times 10^{5}$ for PFA, based on transient viscoelasticity. ${ }^{9}$ Binary FEP/PTFE and PFA/PTFE blends were obtained by kneading the two components in a Brabend- er extruder at $623 \mathrm{~K}$. FEP or PFA was kneaded at $623 \mathrm{~K}$ in the extruder, and then PTFE powders were added to the FEP or PFA melt and mixed until the torque for mixing reached a constant value (for more than $10 \mathrm{~min}$ ). Low $M_{\mathrm{n}}$ of neat PTFE allowed this mixing because of low melt viscosity. Hereafter the blending ratio is expressed by wt $\%$. The blends were compression-molded into sheets $0.5 \mathrm{~mm}$ thick at $623 \mathrm{~K}$. To examine miscibility and crystallization of the blends, the quenched blends were prepared by immersing the sheet samples into chilled water to cool them at a rate of about $30 \mathrm{~K} \mathrm{~min}^{-1}$ after holding for $1 \mathrm{~h}$ at $623 \mathrm{~K}$, and the slowly cooled blends were obtained by cooling the sheet samples at a rate of about $0.5 \mathrm{~K} \mathrm{~min}^{-1}$ from the melt.

DSC measurements were performed at a heating/ cooling rate of $10 \mathrm{~K} \mathrm{~min}^{-1}$, using a Seiko Denshi SSC-5000 differential scanning calorimeter, where phase transition temperature and enthalpy change were calibrated with In and Sn standards. X-Ray diffraction patterns were recorded with a reflection method, using a Rigaku RINT2100-Ultima ${ }^{+}$operated at a $40-\mathrm{kV}$ accelerating potential and a $30-\mathrm{mA}$ emission current. $\mathrm{CuK} \alpha$ radiation was used and the scattering intensities were detected by a scintillation counter as

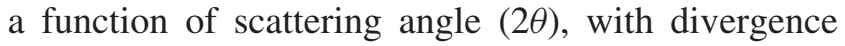
and scattering slits of $1^{\circ}$ and the receiving slit of $0.15 \mathrm{~mm}$. The scattering curves were almost the same with those measured by divergence and scattering slits of $0.5^{\circ}$. The accuracy of scattering angle $(2 \theta)$ was within $\pm 0.01^{\circ}$ by use of a Si polycrystalline standard at $298 \mathrm{~K}$ and precision was within $\pm 0.01^{\circ}$. X-Ray diffraction patterns were taken at $323 \mathrm{~K}$ to $573 \mathrm{~K}$, using a Rigaku high temperature cell, temperature-controlled by a programming controller (Rigaku, PTC-20). Sheets of $\sim 400 \mu \mathrm{m}$ thick were used for FEP/PTFE and PFA/PTFE blends, but powder samples were used for neat PTFE. In the X-Ray diffraction measurements, the sample was heated at $5 \mathrm{~K} \mathrm{~min}^{-1}$ and held at the measured temperature for $1 \mathrm{~h}$. To minimize the temperature difference between the sample and thermocouple, the thermocouple was inserted into a Teflon sheet set on a metal sample holder.

\section{RESULTS}

\section{Crystallization in FEP/PTFE Blends}

(a) DSC Results. Figure 1 shows DSC curves for (a) neat PTFE, (b) neat FEP and (c) FEP/PTFE (50/ 50) blend, where PTFE is a powder sample as received, and neat FEP and FEP/PTFE (50/50) blends are samples slowly cooled from the melt at $623 \mathrm{~K}$ as described in the Experimental. In the second heating run after melting at $623 \mathrm{~K}$, PTFE (a) shows two peaks at 294 and $303 \mathrm{~K}$, and a peak near $604 \mathrm{~K}$ in the higher 


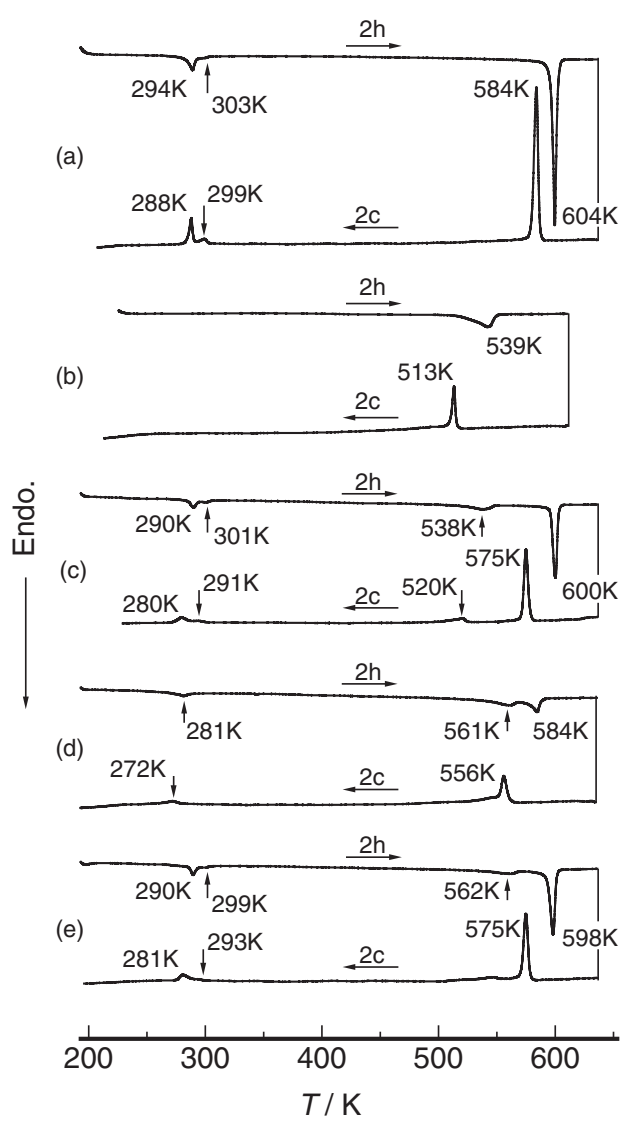

Figure 1. DSC curves for slowly cooled blends: (a) neat PTFE, (b) neat FEP, (c) FEP/PTFE (50/50) blends, (d) neat PFA, and (e) PFA/PTFE (50/50) blends. $2 \mathrm{~h}$ and $2 \mathrm{c}$ represent second heating and second cooling processes, respectively.

temperature region. The former two peaks result from two crystal-crystal transitions of triclinic to hexagonal transformation and of hexagonal to pseudo-hexagonal transformation and often called the room temperature transitions, ${ }^{8,10}$ while the latter peak is caused by the melting of PTFE crystallites. In the second cooling from the melt after the second heating, one crystallization peak and two room temperature transition peaks were seen near $584 \mathrm{~K}$, and at 299 and $288 \mathrm{~K}$, respectively. In neat FEP (b), there is seen one endothermic peak near $539 \mathrm{~K}$ in the second heating, ${ }^{11}$ ascribed to the melting of FEP crystallites. The peaks corresponding to the two room temperature transitions are not shown due to low crystallinity and disordered packing in the crystallites with the bulky HFP moiety. ${ }^{12}$ In FEP/PTFE (50/50) blend (c), there are seen all the peaks observed in neat PTFE and neat FEP: Two room temperature transition peaks at 290 and $301 \mathrm{~K}$ and the melting peaks at 538 and $600 \mathrm{~K}$. In FEP/PTFE blends, FEP and PTFE components are thus separately crystallized. ${ }^{4,5}$

To investigate how the melting and crystallization behavior change with thermal treatments, we performed DSC measurements for two samples, which
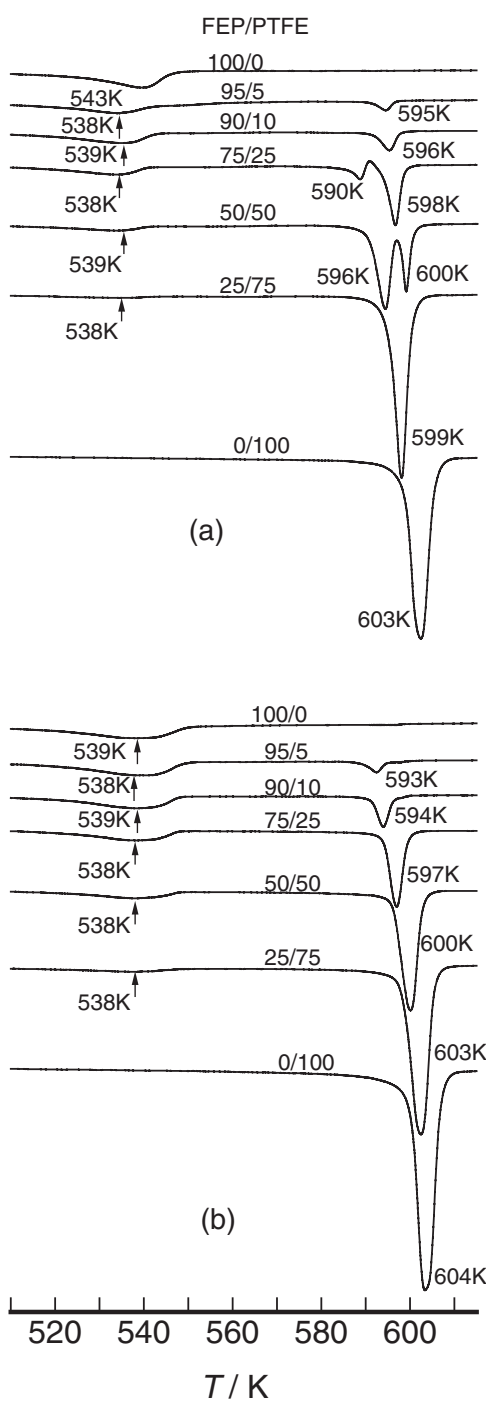

Figure 2. DSC curves at the second heating at 515 to $615 \mathrm{~K}$ for (a) quenched and (b) slowly cooled FEP/PTFE blends.

had undergone different thermal histories; one was quenched from the melt and another was slowly cooled (see the Experimental section). Figure 2 shows DSC heating curves at 515 to $615 \mathrm{~K}$ for FEP/PTFE blends (a) quenched and (b) slowly cooled from the melt. In the quenched blends in (a), the melting peak of PTFE crystallites near $600 \mathrm{~K}$ gradually moved to lower temperatures to become smaller, as FEP content increased, and the melting peak was split into two peaks at FEP contents of 50 and $75 \%$. Another peak due to the melting of FEP crystallites appeared near $540 \mathrm{~K}$ in the blends, to become gradually larger, as FEP content increased, but the peak temperature scarcely changed with FEP content. The melting peak of PTFE crystallites near $600 \mathrm{~K}$ split into two in the quenched blends with 50 and $75 \%$ FEP content. This suggests two PTFE crystallites. This splitting is not visible for the slowly cooled blends in (b), where two melting peaks were seen near 600 and $540 \mathrm{~K}$, cor- 
responding to the melting of PTFE and FEP crystallites, respectively. As FEP content increases, the $600 \mathrm{~K}$ peak moves to lower temperature and becomes smaller, while the $540 \mathrm{~K}$ peak becomes larger but peak temperature is almost independent of FEP content. The thermal behavior of the slowly cooled blends is quite similar to that of quenched blends, except for splitting of the $600 \mathrm{~K}$ peak.

The melting temperature for FEP crystallites, $T_{\mathrm{m}}(\mathrm{F})$, and that for PTFE crystallites, $T_{\mathrm{m}}(\mathrm{P})$, were determined as each peak, and enthalpy changes, $\Delta H_{\mathrm{m}}(\mathrm{F})$ for FEP crystallites and $\Delta H_{\mathrm{m}}(\mathrm{P})$ for PTFE crystallites, were obtained from peak areas. In slowly cooled blends, $T_{\mathrm{m}}(\mathrm{F})$ was $540 \mathrm{~K}$, almost independent of FEP content, while $T_{\mathrm{m}}(\mathrm{P})$ was proportional to FEP content and decreased from $604 \mathrm{~K}$ in neat PTFE to $593 \mathrm{~K}$ in FEP/PTFE $(95 / 5)$ blend. In the quenched blends, changes in $T_{\mathrm{m}}(\mathrm{F})$ and $T_{\mathrm{m}}(\mathrm{P})$ were almost the same as in slowly cooled blends, except for split peaks in the 50 and $75 \%$ FEP blends.

$\Delta H_{\mathrm{m}}(\mathrm{F})$ and $\Delta H_{\mathrm{m}}(\mathrm{P})$ were dependent on FEP content. For PTFE crystallites, change of $\Delta H_{\mathrm{m}}(\mathrm{P})$ with FEP content is approximately expressed in the whole blend range as

$$
\Delta H_{\mathrm{m}}(\mathrm{P}, x)=\left[\Delta H_{\mathrm{m}}(\mathrm{P}, 0) / 100\right] \cdot(100-x),
$$

where $x$ is FEP content in wt $\%$ and $\Delta H_{\mathrm{m}}(\mathrm{P}, x)$ is $\Delta H_{\mathrm{m}}$ at a given $x$ for PTFE crystallites. The slope of eq 1 , $-\Delta H_{\mathrm{m}}(\mathrm{P}, 0) / 100$ was $-0.78 \mathrm{Jg}^{-1}$ for the slowly cooled blends, and $-0.66 \mathrm{~J} \mathrm{~g}^{-1}$ for the quenched blends. For FEP crystallites, a similar equation,

$$
\Delta H_{\mathrm{m}}(\mathrm{F}, x)=\left[\Delta H_{\mathrm{m}}(\mathrm{F}, 100) / 100\right] \cdot x,
$$

is valid for slowly cooled blends and the $\Delta H_{\mathrm{m}}(\mathrm{F}, 100) / 100$ was $0.18 \mathrm{Jg}^{-1}$, where $\Delta H_{\mathrm{m}}(\mathrm{F}, x)$ is $\Delta H_{\mathrm{m}}$ at a given $x$ for FEP crystallites. For quenched blends, the slope of the $\Delta H_{\mathrm{m}}(\mathrm{F}, x) v s . x$ curve changed with $x$. The slope was almost constant and $0.23 \mathrm{~J} \mathrm{~g}^{-1}$ for $x$ more than $75 \%$ FEP, but decreased with decreasing $x$ at less than 75\% FEP. This suggests lowering of crystallization rate of FEP component due to PTFE.

PTFE and FEP components are miscible in the amorphous region and in the molten state. ${ }^{13}$ However, the present DSC results reveal that FEP and PTFE crystallites are separately formed from the melt mixture of FEP and PTFE. When the melt mixture is quenched, it can be conjectured that during quenching from the melt, especially for 50 and $75 \%$ blends, PTFE crystallites are formed and PTFE crystallites incorporating FEP segments are produced, to form two types of PTFE crystallites in the quenched blends, and finally, at $520 \mathrm{~K}$, FEP crystallites are formed. On the second heating for the FEP/PTFE (75/25) blend (Figure 2a), an exothermic peak is seen at high temperature of the $590 \mathrm{~K}$ peak, and the $598 \mathrm{~K}$ peak ap- pears, which suggests that after PTFE crystallites incorporating FEP segments melt, recrystallization of PTFE crystallites may take place and PTFE crystallites, together with those produced during quenching, melt at $598 \mathrm{~K}$. On slow cooling, first PTFE crystallites are formed and FEP crystallites are produced. This seems reasonable, because the rate of crystallization for PTFE is considered to decrease with the FEP component and different cooling rates may cause different crystallization behavior.

Figure 3 shows second heating DSC curves in the room temperature range for (a) the quenched and (b) slowly cooled blends. In neat PTFE, there are seen two peaks near 294 and $303 \mathrm{~K}$, irrespective of thermal treatment. In the quenched blends, the $294 \mathrm{~K}$ peak almost disappears at FEP content larger than 95\%, while in the slowly cooled blends, the $294 \mathrm{~K}$ peak is still seen in the 95\% FEP blend. These phenomena are explained by a disordering of PTFE crystallites with the bulky HFP units in FEP component. There is a signif-

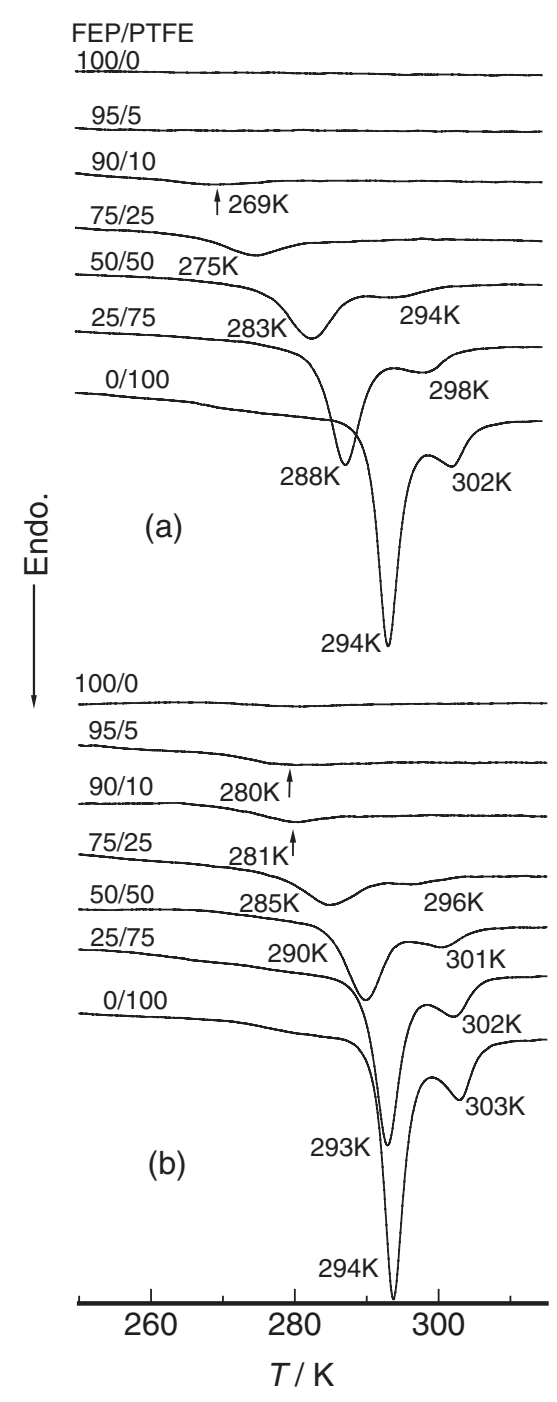

Figure 3. DSC curves at the second heating at room temperature for (a) quenched and (b) slowly cooled FEP/PTFE blends. 
icant difference in DSC curves between the quenched and slowly cooled blends: Shifts of the 294 and $303 \mathrm{~K}$ peaks with the addition of FEP are larger in the quenched blends than in the slowly cooled blends. In slowly cooled blends, the peak temperature, $T_{294 \mathrm{~K}}$, decreased in proportion to FEP content, from $294 \mathrm{~K}$ for neat PTFE to $280 \mathrm{~K}$ for the $90 \%$ FEP blend, while in the quenched blends, from $294 \mathrm{~K}$ for neat PTFE to $269 \mathrm{~K}$ for the $90 \%$ FEP blend. The lowering of $T_{294 \mathrm{~K}}$ and $T_{303 \mathrm{~K}}$ with FEP content suggests the PTFE crystallites is somewhat disturbed by the FEP component but the orderliness in the crystallites appears to increase by annealing (slow cooling). Enthalpy changes, $\Delta H_{294 \mathrm{~K}}$ and $\Delta H_{303 \mathrm{~K}}$ for $294 \mathrm{~K}$ and $303 \mathrm{~K}$ transitions, respectively, decrease as FEP content increases, satisfying the following equations,

$$
\Delta H_{294 \mathrm{~K}}(x)=\Delta H_{294 \mathrm{~K}}(0) \cdot(100-x) / 100
$$

and

$$
\Delta H_{303 \mathrm{~K}}(x)=\Delta H_{303 \mathrm{~K}}(0) \cdot(100-x) / 100,
$$

respectively.

Thus PTFE crystallites are formed separately from FEP crystallites. A transition exists near $278 \mathrm{~K}$ in neat FEP with 1 mol \% HFP, and in FEP/PTFE blends, this transition is seen in addition to two room temperature transitions of neat PTFE. Our neat FEP did not show room temperature transition on DSC curves, due to high HFP content of $10 \mathrm{~mol} \%$.

(b) X-Ray Diffraction Results. Figure 4 shows XRay diffraction patterns at room temperature for neat FEP quenched from the melt and neat PTFE powders. A sharp peak is observed at a scattering angle $(2 \theta)$ of $17.76^{\circ}$ for neat FEP and at $18.04^{\circ}$ for neat PTFE, both assigned to (100) reflection. The spacing of (100) re-

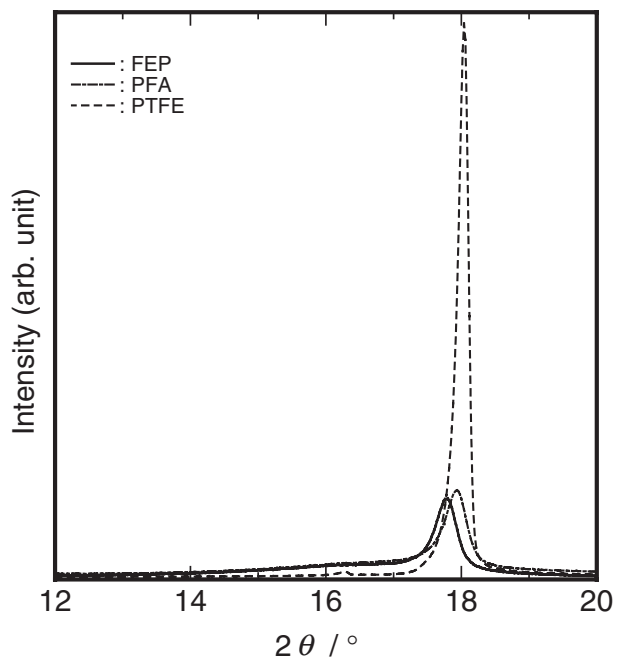

Figure 4. X-Ray diffraction patterns for neat FEP, neat PFA, and neat PTFE at room temperature. FEP and PFA were quenched from melt.

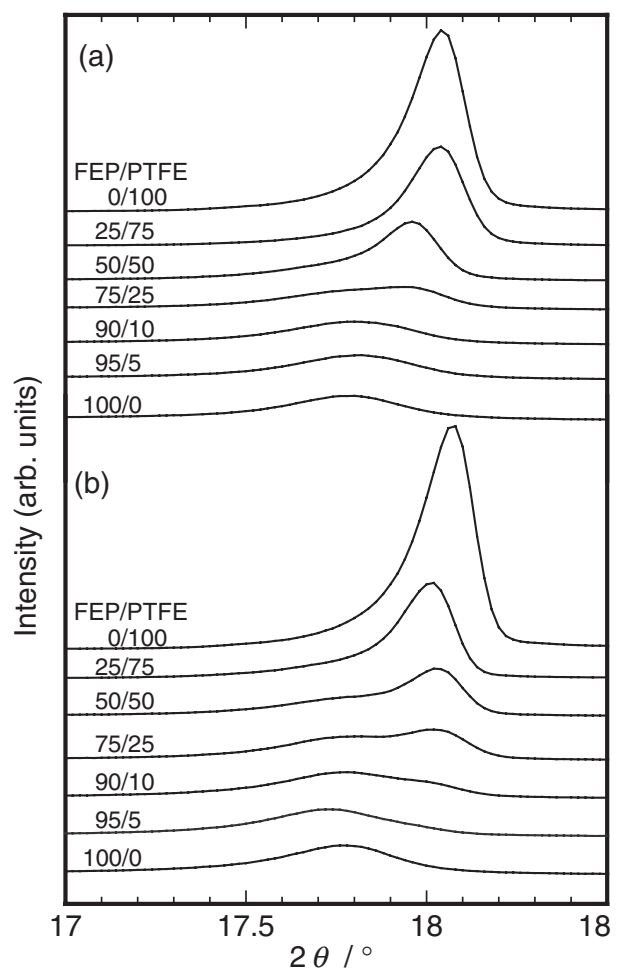

Figure 5. X-Ray diffraction patterns of FEP/PTFE blends at room temperature: (a) quenched blends and (b) slowly cooled blends. FEP content of each blend is shown.

flection $\left(d_{100}\right)$ was estimated as $4.99 \AA$ for neat FEP, and $4.91 \AA(a=5.67 \AA)$ for neat PTFE, consistent with literature values $\left(a=5.75 \AA\right.$ for $\mathrm{FEP}^{14-16}$ and $5.66 \AA$ for PTFE $^{9}$ ). A broad halo peak appeared around $16^{\circ}$, from the amorphous region. These characteristics are also seen for all FEP/PTFE blends.

Figure $5 \mathrm{a}$ and $\mathrm{b}$ show X-Ray diffraction intensity vs. $2 \theta$ curves at room temperature for (a) quenched and (b) slowly cooled FEP/PTFE blends, respectively. In quenched blends in (a), one sharp peak is seen near $2 \theta$ of $18^{\circ}$ for neat PTFE, corresponding to the (100) reflection and as FEP content increases, the $18^{\circ}$ peak moves to lower angles and height decreases, and at FEP content $\geq 90 \%$, the peak skips to $17.8^{\circ}$ (and to $17.76^{\circ}$ for neat FEP). When FEP content is $75 \%$, the peak splits into two peaks near $17.8^{\circ}$ and $18^{\circ}$, due to FEP and PTFE crystallites, respectively. In the slowly cooled blends in (b) this splitting is more distinctly seen. This supports that PTFE and FEP crystallites are separately formed in FEP/PTFE blends.

Figure 6 shows plots of $d_{100} v s$. FEP content, where $d_{100}(\mathrm{~F})$ and $d_{100}(\mathrm{P})$ represent (100) spacings of FEP and PTFE crystallites, respectively. In this figure, the $d_{100}(\mathrm{~F})$ and $d_{100}(\mathrm{P})$ are read simply from the patterns. When FEP content is between 50 and $90 \%$, the plots have data points of both $d_{100}(\mathrm{~F})$ and $d_{100}(\mathrm{P})$. In the quenched blends, $d_{100}(\mathrm{P})$ of PTFE crystallites increases in proportion to FEP content but in 


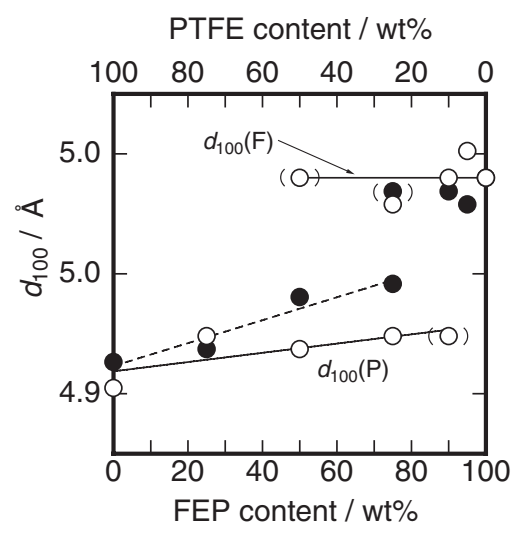

Figure 6. Plots of d-spacing of (100) reflection $\left(d_{100}\right)$ at room temperature versus FEP content for FEP/PTFE blends: $\bigcirc$, slowly cooled blends; $\bullet$, quenched blends; $(\bigcirc)$ and $(\bullet)$ indicate value corresponding to weak shoulder peak position of each diffraction pattern. $\mathrm{F}$ and $\mathrm{P}$ in parentheses indicate values related to FEP and PTFE crystallites, respectively.

the slowly cooled blends, the increase becomes less. The different slope is explained as follows: During quenching from the melt, FEP component perturbs the formation of PTFE crystallites and makes PTFE crystallites disordered, leading to the larger $d_{100}(\mathrm{P})$ in quenched blends. On slowly cooling, however, PTFE crystallized without incorporating FEP, to produce more ordered PTFE crystallites. The $d_{100}(\mathrm{~F})$ of FEP crystallites is almost independent of FEP content and thermal history. Since FEP crystallites are formed after the crystallization of PTFE during cooling from the melt, the crystallization may not be so affected by PTFE, resulting in no dependence on FEP content, as seen from DSC. Consequently, X-Ray diffraction indicates the presence of two separated crystallites, FEP and PTFE crystallites in the present FEP/PTFE blends, well consistent with the conclusion by DSC.

For a more information on crystallization, we preformed X-Ray diffraction measurements at different temperatures at 323 to $573 \mathrm{~K}$. Figure 7 shows variation in X-Ray diffraction patterns with FEP content for slowly cooled FEP/PTFE blends (a) at $323 \mathrm{~K}$ and (b) at $573 \mathrm{~K}$. At $323 \mathrm{~K}$, the (100) reflection peaks for the blends are seen as two peaks around 17.7 and $17.9^{\circ}$, which originate in FEP and PTFE crystallites, respectively, and a broad amorphous peak appears around $16^{\circ}$. These three peaks are resolved as follows and are drawn as broken curves in the figure. Each resolved peak was assumed to obey a pseudo-Voigt function as a linear combination of Lorentz and Gauss distribution functions. The three resolved peaks were obtained by the best fit of the sum of the three peaks to the experimental curve, using the Davidon-Fletcher-Powell optimization method. ${ }^{17-20}$ The area for each peak was calculated as the sum of small trapezoids. At
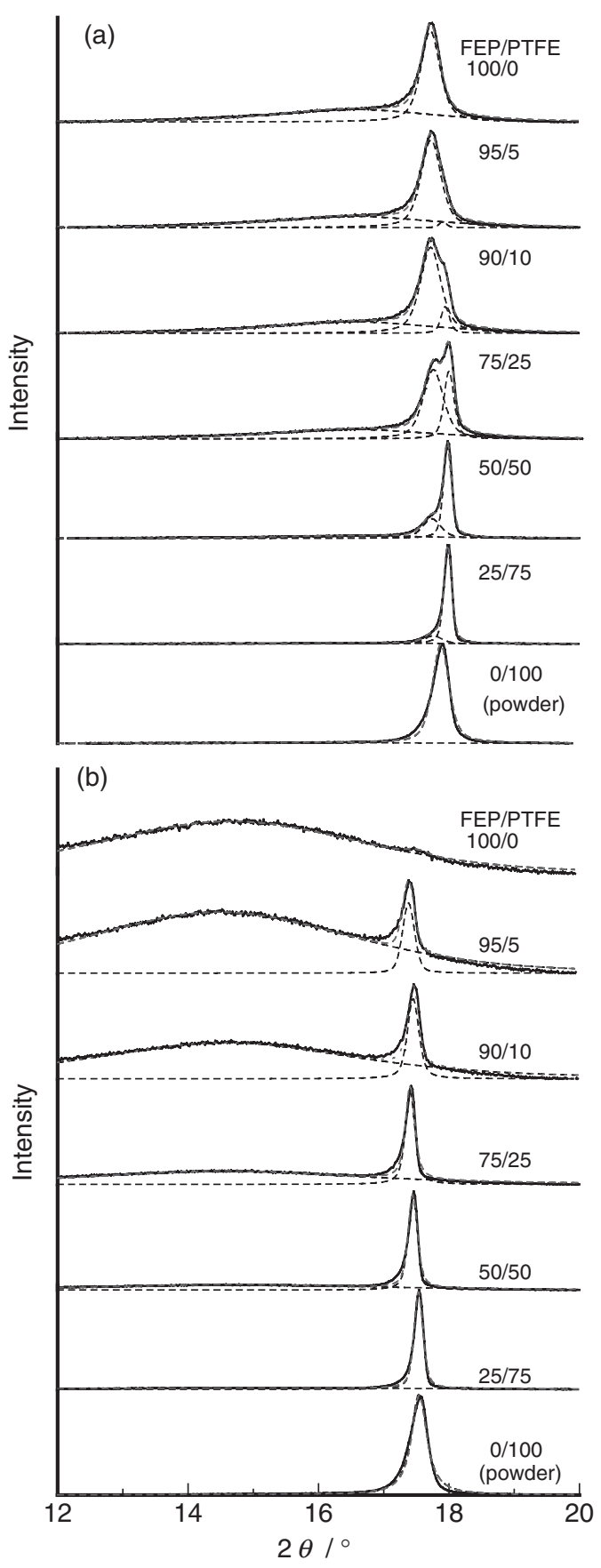

Figure 7. X-Ray diffraction patterns of FEP/PTFE blends at (a) $323 \mathrm{~K}$ and (b) $573 \mathrm{~K}$. Solid curves are observed patterns and dotted curves are resolved peaks.

$323 \mathrm{~K}$ (Figure 7a), the three peaks appear in FEP/ PTFE blends, which come from FEP and PTFE crystallites and the amorphous phase, respectively. As temperature elevated, the peak from PTFE crystallites became relatively larger, and that from FEP crystallites was inversely smaller. At $573 \mathrm{~K}$ above the melting temperature of FEP crystallites ( $539 \mathrm{~K}$ determined by DSC) (Figure 7b), the peak from the FEP crystallites completely disappeared, but that from the PTFE crystallites existed and the amorphous peak was considerably larger (especially at FEP content 100, 95 or 
90\%). At $323 \mathrm{~K}$ (a), the PTFE peak becomes relatively smaller with increasing FEP content, and FEP and amorphous peaks, are inversely larger. This was seen at all temperatures between 323 and $523 \mathrm{~K}$ (figures not shown), but at $573 \mathrm{~K}$, the FEP crystallites completely disappear for all blends, indicating that FEP crystallites completely melt at $573 \mathrm{~K}$, independent of PTFE crystallites. In neat FEP, only the amorphous peak is seen. A PTFE peak distinctly exists at $573 \mathrm{~K}$ below the melting temperature of PTFE (604 K). Our equipment, did not allow the measurements above $573 \mathrm{~K}$. These temperature-dependent X-Ray results show that PTFE and FEP crystallites are formed separately, independent of the FEP/PTFE blend.

Figure $8 \mathrm{a}$ shows variation in $d_{100}(\mathrm{~F})$ and $d_{100}(\mathrm{P})$ with FEP content in slowly cooled FEP/PTFE blends at different temperatures. $d_{100}(\mathrm{~F})$ and $d_{100}(\mathrm{P})$ are almost independent of FEP content, and $d_{100}(\mathrm{~F})$ is larger than $d_{100}(\mathrm{P})$. In Figure $9, d_{100}(\mathrm{~F})$ and $d_{100}(\mathrm{P})$ are plotted as a function of temperature for all blends. At each FEP content, $d_{100}(\mathrm{~F})$ of the FEP crystallites increases in proportion to temperature, and temperature variation scarcely depends on FEP content, except for the $25 \%$ FEP blend. The thermal expansion coefficient of the (100) spacing in FEP crystallites was estimated as $6 \times 10^{-4}$. In the $25 \%$ FEP blend, the plots were concavely curved, deviating largely from the data for the other blends, presumably due to large PTFE content. PTFE crystallite, the $d_{100}(\mathrm{P})$ did not change

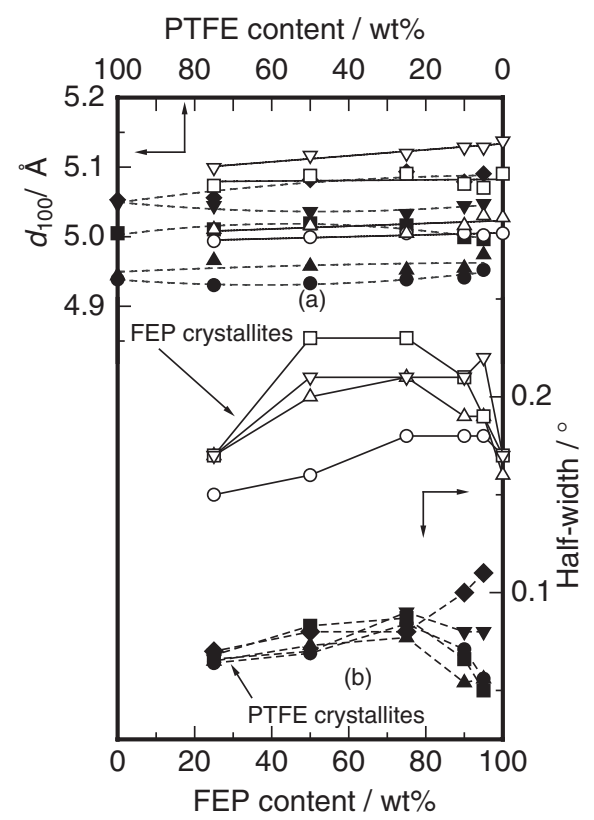

Figure 8. Plots of (a) d-spacing $\left(d_{100}\right)$ and (b) half-width of the (100) reflection peak versus FEP content for FEP/PTFE blends at $\bigcirc$ and $\bullet, 323 \mathrm{~K} ; \triangle$ and $\boldsymbol{\Delta}, 373 \mathrm{~K}$; $\square$ and $\boldsymbol{\square}, 473 \mathrm{~K}$; $\nabla$ and $\nabla, 523 \mathrm{~K} ; \diamond, 573 \mathrm{~K}$. Open symbols and solid lines represent data for FEP crystallites, and closed symbols and broken lines represent data for PTFE crystallites.

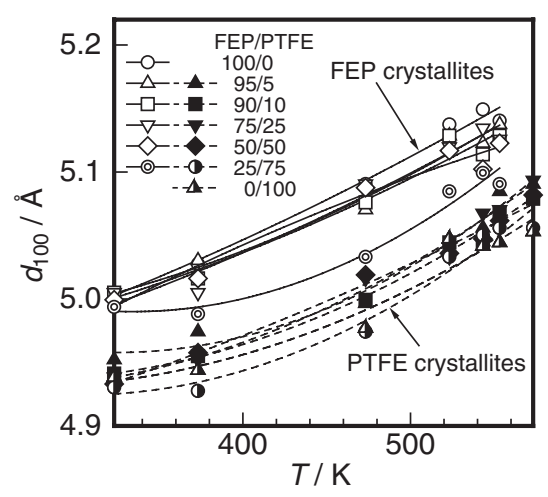

Figure 9. Plots of $d_{100} v s$. temperature at various FEP content for FEP/PTFE blends as indicated in the figure. Open symbols and solid curves represent data for FEP crystallites, and closed symbols and broken curves represent data for PTFE crystallites.

by FEP content, but $d_{100}(\mathrm{P})$-temperature plots are somewhat curved for all FEP. Thus thermal expansion coefficient of the (100) spacing in PTFE crystallites is dependent on temperature. PTFE crystallites undergo the room temperature transitions of triclinic (13/6 helices of $\mathrm{CF}_{2}$ chain) to hexagonal (15/7 helices) at $294 \mathrm{~K}$ and of hexagonal to pseudo-hexagonal at $303 \mathrm{~K}$, and as temperature increases beyond $303 \mathrm{~K}$, the pseudo-hexagonal structure may become more disordered, due to of right- and left-handed helices in one $\mathrm{CF}_{2}$ main chain. ${ }^{10}$ The temperature-dependent thermal expansion coefficient for $d_{100}(\mathrm{P})$ may be explained by progressive decrease in orderliness of molecular packing in the crystallites with temperature.

The half-width at half-maximum of the (100) reflection peak is correlated with orderliness of molecular packing in the crystallites. In Figure 8b, halfwidths for the separately formed FEP and PTFE crystallites are plotted against FEP content and temperature. At each temperature, the half-width for the FEP crystallites abruptly increases from that of neat FEP, as PTFE component is blended, and at $25 \%$ FEP (75\% PTFE), decreases to the initial value. The half-width becomes larger with temperature but at $25 \%$ FEP, appears unchanged with temperature. For PTFE crystallites, the half-width is distinctly (about $40 \%$ ) smaller than that of FEP crystallites, and hardly dependent on FEP content or temperature, although it shows some temperature dependency for blends with FEP content of 90-95\%. Orderliness of molecular packing is larger in PTFE crystallites than in FEP crystallites, which explains the different behavior of the two crystallites with temperature and blending ratio.

\section{Crystallizations in PFA/PTFE Blends}

(a) DSC Results. Figure 1 are DSC thermographs for slowly cooled neat PTFE (a), neat PFA (d), and 


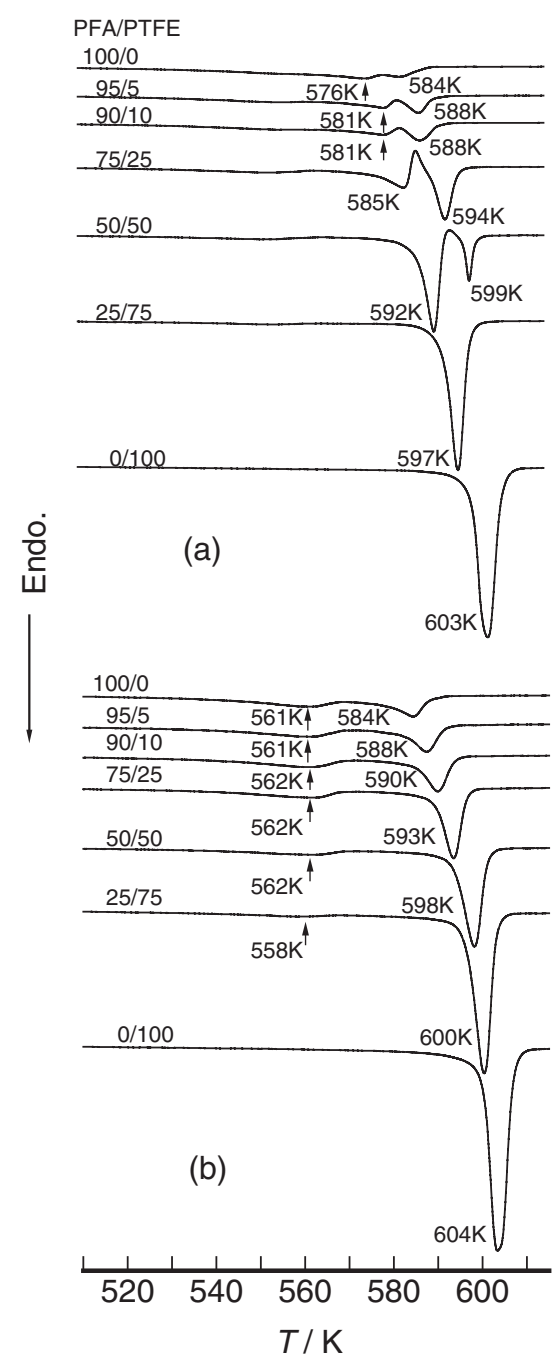

Figure 10. DSC curves at second heating at 515 and $615 \mathrm{~K}$ for (a) quenched and (b) slowly cooled PFA/PTFE blends.

PFA/PTFE (50/50) blend (e). In the second heating, there are seen two room temperature transition peaks at $300 \mathrm{~K}$ and $604 \mathrm{~K}$ for neat PTFE, and corresponding peaks at 281 and $584 \mathrm{~K}$ for neat PFA, and 290 and $598 \mathrm{~K}$ for PFA/PTFE (50/50) blend. In cooling after the second heating, room temperature transitions and crystallization peaks are observed, corresponding to those in the heating. Figure 10 shows the second heating DSC curves in the melting temperature range for the PFA/PTFE blends quenched, (a), and slowly cooled, (b), from the melt. In the quenched blends (a), the melting peak shifts to lower temperatures, as PFA content increases and when PFA content is more than $50 \%$, splits into two peaks. ${ }^{6}$ The low and high temperature peaks mainly come from the PFA and PTFE crystallites, respectively, and between the two peaks, an exothermic peak due to recrystallization is observed, as in the FEP/PTFE blends (Figure 2a). In the slowly cooled blends (b), the melting endotherm is seen as a single peak, for all blend ratios, although

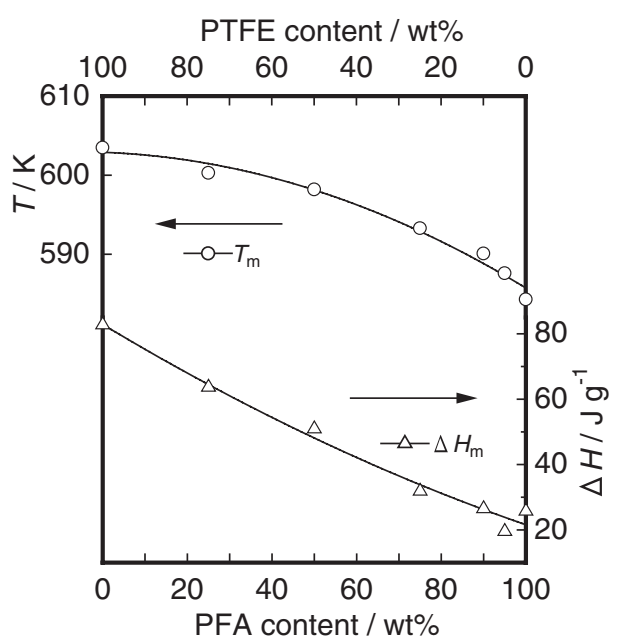

Figure 11. Plots of PFA melting temperature $\left(T_{\mathrm{m}}\right)$ and melting enthalpy $\left(\Delta H_{\mathrm{m}}\right) v s$. PFA content for slowly cooled PFA/PTFE blends.

a very small peak appears near $560 \mathrm{~K}$. The melting peak becomes smaller and moves to lower temperatures, as PFA content increases. The small $560 \mathrm{~K}$ peak can be an annealing peak caused by slow cooling from the melt, ${ }^{15,20}$ because the peak is depressed in the quenched blends. The melting endotherm appeared as a single peak even when DSC was scanned at the heating rate of $1 \mathrm{~K} \mathrm{~min}^{-1}$. The single peak in the slowly cooled blends suggests that PFA and PTFE components are cocrystallized.

In Figure 11, melting temperature $\left(T_{\mathrm{m}}\right)$ and enthalpy change $\left(\Delta H_{\mathrm{m}}\right)$ are plotted against PFA content for slowly cooled blends. $T_{\mathrm{m}}$ gradually increases with PTFE content but the plots deviate convexly from a straight line, while the $\Delta H_{\mathrm{m}}-\mathrm{PFA}$ content curve is slightly concave, suggesting interactions between PTFE and PFA chains. The $-\mathrm{OCF}_{2} \mathrm{CF}_{2} \mathrm{CF}_{3}$ side chain of PVE units in PFA may be not incorporated into the PTFE crystallites, ${ }^{15,20}$ although the TFE segments of PFA may be incorporated into PTFE crystallites. The side chain cause disordered packing in the PTFE crystallites, resulting in lower melting temperature with the addition of PFA, although the melting temperature is also correlated with lamellar thickness.

Figure 12 shows DSC curves in the room temperature transitions range between 250 and $315 \mathrm{~K}$ for PFA/PTFE blends (a) quenched, and (b) slowly cooled, from the melt. The two room temperature transition peaks are seen at 294 and $303 \mathrm{~K}$ for neat PTFE. The $294 \mathrm{~K}$ peak moves to lower temperature and becomes smaller with PFA content, but is clearly observed even in neat PFA, contrary to that in FEP/ PTFE blends, owing to the small content of PVE comonomer in PFA ( $2 \mathrm{~mol} \%)$. The shift to lower temperature with the addition of PFA is larger in quenched blends than in slowly cooled blends. The 


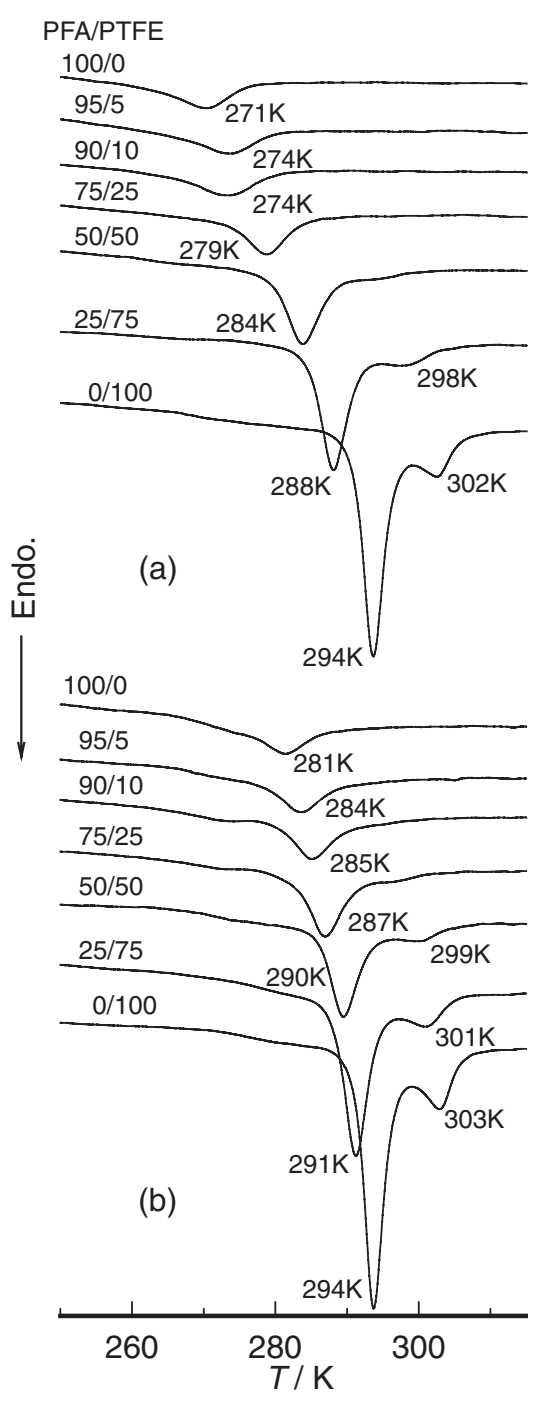

Figure 12. DSC curves at the second heating in the room temperature range for (a) quenched and (b) slowly cooled PFA/PTFE blends.

growth rate of PTFE-type crystallites, cocrystallized from the PFA/PTFE melt, may becomes slow with $\mathrm{PFA}^{7}$ and in the quenched blends, more disordered crystallites may form. As molecular packing in the crystallites is more disordered, the transition temperature is more lowered. In slowly cooled blends, $\Delta H_{294 \mathrm{~K}} \Delta H_{303 \mathrm{~K}}$ decreased from $13 \mathrm{~J} \mathrm{~g}^{-1}$ for neat PTFE to $2.5 \mathrm{~J} \mathrm{~g}^{-1}$ for neat PFA for the same reason above.

(b) X-Ray Results. In Figure 4, the X-Ray diffraction pattern at room temperature for the quenched neat PFA is shown together with that for PTFE. In neat PFA, the (100) reflection peak is observed at $2 \theta$ of $17.92^{\circ}$, which is slightly lower than that for neat PTFE $\left(18.04^{\circ}\right)$. The spacing $\left(d_{100}\right)$ of PFA crystallites is estimated to be $4.95 \AA$ and thus, the hexagonal $a$ axis, $a$, is $5.71 \AA$, which is consistent with the literature value $(5.68 \AA){ }^{15,16}$ The amorphous halo peak is seen around $2 \theta$ of $16^{\circ}$. Figure 13 shows variation of the (100) re-

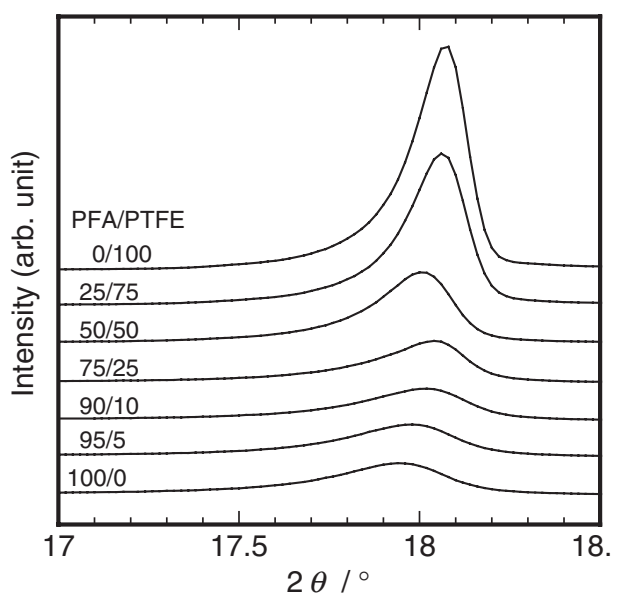

Figure 13. X-Ray diffraction patterns of slowly cooled PFA/ PTFE blends at room temperature. PFA content of each blend is indicated.

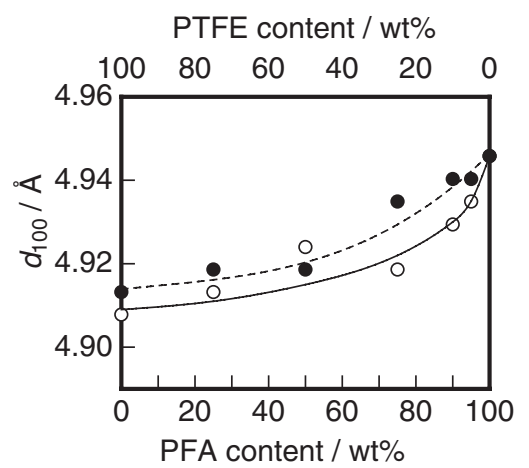

Figure 14. Plots of $d_{100}$ at room temperature $v s$. PFA content in PFA/PTFE blends: $\bigcirc$, slowly cooled blends; $\bullet$, quenched blends.

flection peak with PFA content at room temperature for slowly cooled PFA/PTFE blends. In contrast to FEP/PTFE blends (Figure 5), patterns for all the blend ratios appear composed of a single peak, indicative of cocrystallization of PFA and PTFE components. When PFA is less than $50 \%$, the peak position is almost unchanged with PFA content, but as the PFA content increases beyond $50 \%$, the peak gradually shifts to lower angles to become smaller and broader. This is more easily understood from Figure 14, which shows data for quenched blends. $d_{100}$ for the quenched blend (broken curve) are larger than that for the slowly cooled blend (solid curve), except for 50\% PFA, consistent with the conclusion that the blend has time enough to form PTFE crystallites not incorporating $-\mathrm{OCF}_{2} \mathrm{CF}_{2} \mathrm{CF}_{3}$ side chain of PVE units. At 50\% PFA, $d_{100}$ for the slowly cooled blend is larger than that for the quenched blend, due to lowering of the transition temperature with PFA (see Figure 12), because at $323 \mathrm{~K}$, at which all the blends are in the pseudo-hexagonal state, $d_{100}-\mathrm{PFA}$ content curve is smooth 


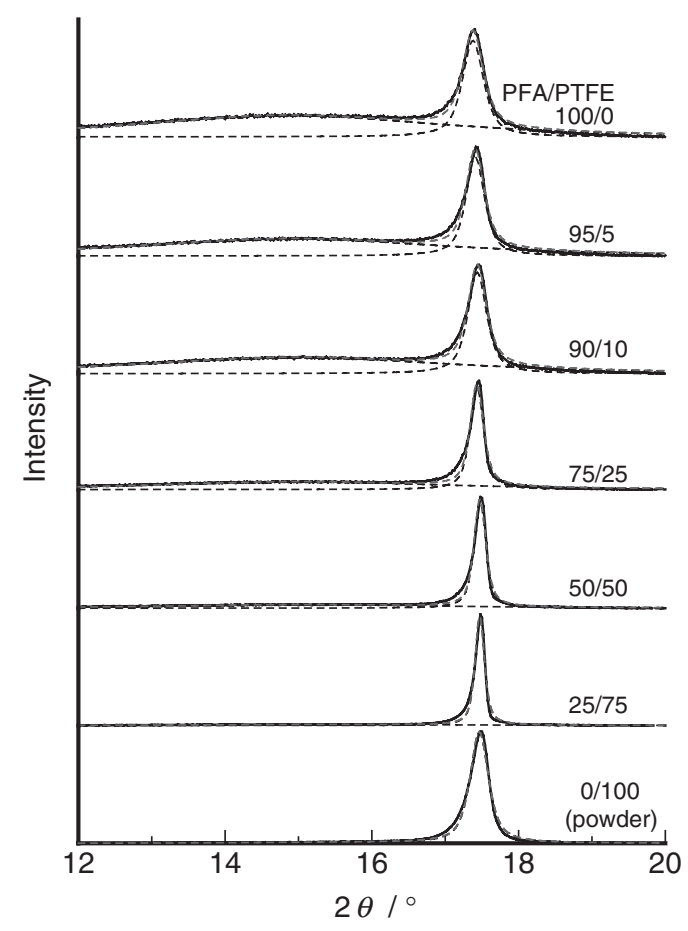

Figure 15. X-Ray diffraction patterns at $563 \mathrm{~K}$ of PFA/PTFE blends. Solid curves are patterns and broken curves, resolved peaks.

in the whole PFA content range (see also Figure 16b).

Figure 15 shows the $\mathrm{X}$-Ray diffraction patterns at $563 \mathrm{~K}$ for PFA/PTFE blends. The samples were slowly cooled from the melt at $623 \mathrm{~K}$ to room temperature prior to the measurements. All patterns were resolved into two peaks around $16^{\circ}$ and $18^{\circ}$ using the curve fitting method described already. The $18^{\circ}$ peak is assigned to the (100) reflection of PTFE-type crystallites, and the $16^{\circ}$ peak is attributed to a halo from the amorphous region. As PFA content increases, the (100) reflection peak shifts to lower angles but appears as a single peak at any PFA content. Similar measurements were done at $323-563 \mathrm{~K}$. The temperature $323 \mathrm{~K}$ is above the crystal-crystal transitions temperature and $563 \mathrm{~K}$ is below the melting temperature of neat PFA. As temperature was elevated, the (100) reflection peak gradually shifted to lower $2 \theta$, from $17.9^{\circ}$ at $323 \mathrm{~K}$ to $17.4^{\circ}$ at $563 \mathrm{~K}$, but appeared as a single peak at all temperatures. These results support the formation of cocrystallites from PFA and PTFE in the blends at any blend ratio.

Figure 16 summarizes the parameters for the (100) reflection derived from the curve fitting. Figure 16b depicts plots of $d_{100} v s$. PFA content at different temperatures. $d_{100}$ appears larger at PFA higher than $75 \%$, but $d_{100}$ is rather independent of the blend ratio at all temperatures, as with FEP/PTFE blends in Figure 8a. Temperature dependence of $d_{100}$ is shown in Figure 16a. As temperature increases, $d_{100}$ at each

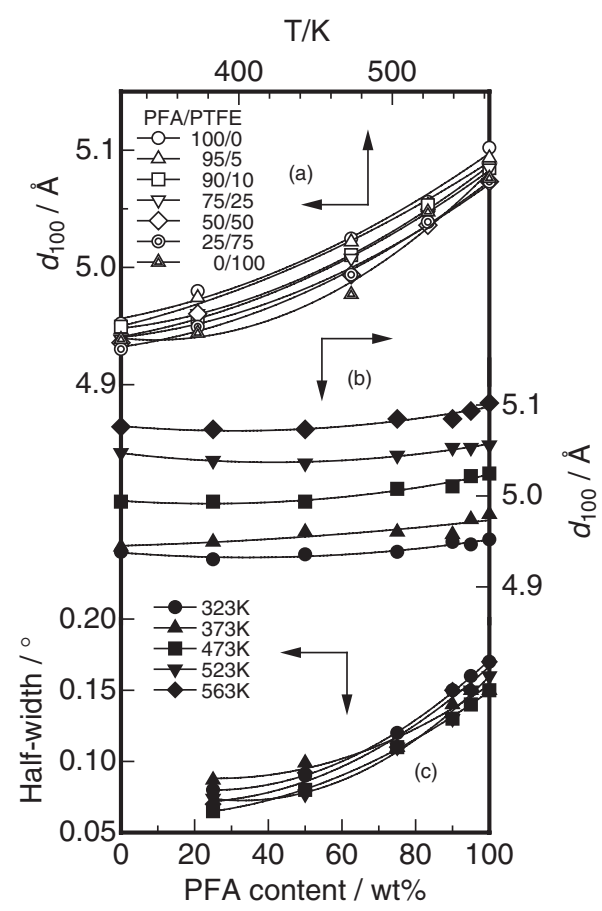

Figure 16. (a) Plots of $d_{100} v s$. temperature for PFA/PTFE blends with various PFA content indicated, and plots of (b) $d_{100}$ and (c) half-width of (100) reflection vs. PFA content for PFA/ PTFE.

blend ratio concavely increases, from $4.94 \AA$ at 323 $\mathrm{K}$ to $5.09 \AA$ at $563 \mathrm{~K}$ in PFA/PTFE (50/50) blend. This temperature dependence is similar to that in separatedly formed PTFE crystallites in FEP/PTFE blends (Figure 9). Therefore, in PFA/PTFE blends, PFA and PTFE components are cocrystallized, perhaps incorporating TFE segments of both components, to form PTFE-type crystallites. Figure 16c shows variation of the half-width with PFA content in PFA/PTFE blends at different temperatures. The half-width is almost independent of temperature, but increases with PFA, in contrast to FEP/PTFE blends (Figure 8b): In FEP/PTFE blends, the half-width of the separately formed PTFE crystallites was $0.07^{\circ}$, almost independent of FEP content, but in PFA/PTFE blends, half-width changed from about $0.07^{\circ}$ in the $25 \%$ PFA blend to $0.16^{\circ}$ in neat PFA. The $-\mathrm{OCF}_{2}-$ $\mathrm{CF}_{2} \mathrm{CF}_{3}$ side chain in PFA may be not incorporated in the PTFE crystallites and as the result, and may be located outside the crystallites. ${ }^{15,16,20-22}$ This may cause disordered packing in the crystallites, which explains increase in (100) half-width by addition of PFA.

\section{DISCUSSION}

Compatibility in the Amorpohous and Molten States

Solubility parameters $\delta$ of component polymers were calculated with the same as by Pucciariello et 
$a l .,{ }^{5}$ using $\delta=\rho\left(\left(\Sigma F_{\mathrm{i}}\right) / M\right)$, where $\rho$ is the density of the polymer (and $2.3 \mathrm{~g} / \mathrm{cm}^{3}$ for all component polymers), $F_{\mathrm{i}}$ is the molar attraction constant (values in ref 23 were used), and $M$ is the molecular mass of the component repeating unit. For the copolymers, $\delta$ of the comonomers were summed with their molar fraction. $\delta$ for PTFE, FEP (10 mol \% HFP), and PFA were all about $5.3\left(\mathrm{cal} \mathrm{cm}^{-3}\right)^{0.5}$, which suggests a good compatibility for FEP/PTFE and PFA/PTFE blends. The compatibility of the two components in these blends was confirmed experimentally by dynamic mechanical (DM) studies and that for both FEP/ PTFE $^{13}$ and PFA/PTFE ${ }^{3,6}$ blends; the $\alpha$ relaxation attributable to a cooperative segmental motion in the amorphous region above $T_{\mathrm{g}}{ }^{24-26}$ is seen as a single peak over all blend ratios.

\section{Crystallization Behavior}

Pucciariello et al. ${ }^{5}$ reported the formation of two separated crystallites, FEP and PTFE crystallites, in FEP ( 2 mol \% HFP)/PTFE blends. In the present work, the same crystallization behavior occurred in FEP (10 mol \% HFP)/PTFE blends. Since FEP and PTFE components are separately crystallized when HFP content is $2 \mathrm{~mol} \%$, it is quite natural that they are so when HFP content is $10 \mathrm{~mol} \%$. As for crystallization behavior in PFA/PTFE blends, some discrepancies are recognized in previous reports: ${ }^{3-7}$ In PFA (i.e., PVE content is $2 \mathrm{~mol} \%$ )/ PTFE blends, the two components were cocrystallized, forming PTFE-type crystallites. Runt et al. $^{3}$ reported that in PFA1-2 (i.e., PVE content is 1-2 mol\%)/PTFE blends, the two components are separately crystallized, although suggesting a possibility of cocrystallizations under a very rapid crystallization condition. Even in PFMVE2/PTFE blends, Pucciariello et al. ${ }^{4}$ reported that PFMVE2 and PTFE crystallites are separately formed. The content of MVE units having the $-\mathrm{OCF}_{3}$ side group in PFMVE2 was $2 \mathrm{~mol} \%$.

\section{Factors determining Crystallization Behaviors}

It may be necessary to investigate how crystallization is affected by:

(1) chemical structure in PFAVE copolymers; (a) length of perfluorosidechains, for example, $-\mathrm{OCF}_{3}$ in $\mathrm{MVE}$ and $-\mathrm{OCF}_{2} \mathrm{CF}_{2} \mathrm{CF}_{3}$ in PVE, and comonomer content in the copolymers, and (b) degree of tendency for the comonomer units to be in blocks, in the nominally random FEP and PFA copolymers. In FEP ( $1 \mathrm{~mol} \% \mathrm{HFP}) / \mathrm{PFMVE} n^{5}$ blends, crystallization behavior changed sensitively with the value of $n$ in PFMVE $n$, where $n$ is the comonomer content in mol \%: When $n=2$, the FEP and PFMVE2 components are cocrystallized, but when $4 \leq n \leq 10$, are separately crystallized.
(2) how two copolymers mix at the molecular level when the binary blends are prepared. We obtained binary FEP/PTFE and PFA/PTFE blends by kneading the two polymers in a Brabender extruder as described in the Experimental section. The FEP or PFA pellets were kneaded at $623 \mathrm{~K}$ and then PTFE powders were added to the FEP or PFA melts, and mixed until torque during the mixing reached a constant value. Sheets were obtained by compression-molding from the melt at $623 \mathrm{~K}$. In the previous work, ${ }^{3-5}$ the binary powder mixtures were obtained by mixing aqueous PTFE dispersion with aqueous FEP or PFAVE dispersions and drying, and then, mixing. The powder mixtures were sandwiched between two Kapton sheets and held at $637 \mathrm{~K}$ for $15 \mathrm{~min}$ to melt them. The difference in preparation of the blends may occasionally be responsible for discrepancies on the crystallization behavior obtained.

(3) thermal history which the blends have underwent.

(4) molecular weights of components. We used PTFE with low $M_{\mathrm{n}}$ of $1 \times 10^{5}$, which is comparable to that of FEP or PFA $\left(2 \times 10^{5}\right)$, favoring good compatibility. Commercial PTFE with high $M_{\mathrm{n}}$ was used, for example, $3.6 \times 10^{5}$ for Teflon 3170 . The difference in $M_{\mathrm{n}}$ of two components plays an important role of compatibility in amorphous and molten states, which may occasionally affect crystallization behavior.

Noguchi and Ishiwari ${ }^{7}$ investigated crystallization behavior of FEP (5.5 mol \% HFP)/PFA ( $1 \mathrm{~mol} \%$ PVE) blends. Isothermal crystallization rate of PFA at $570 \mathrm{~K}$ changed from $0.38 \mathrm{~min}^{-1}$ for neat PFA to $0.6 \mathrm{~min}^{-1}$ for the $25 \%$ FEP blend. Spherulite growth rate in diameter of PFA decreased from 0.0217 $\mu \mathrm{m} \mathrm{s}^{-1}$ for neat PFA to $0.004 \mu \mathrm{m} \mathrm{s}^{-1}$ for the 25 mol \% PFA blend. These observations indicate that the crystallization of fluorinated copolymer blends is significantly influenced by comonomer content and cooling rate. It is reasonable to conclude that the appearance of two kinds of PTFE crystallites in the quenched FEP/PTFE and PFA/PTFE blends are related to the crystallization rate of PTFE.

\section{CONCLUDING REMARKS}

This work studies crystallization behavior for FEP/ PTFE and PFA/PTFE blends, and concludes that FEP and PTFE components are separatedly crystallized in the FEP/PTFE blends, but in the PFA/PTFE blends, PFA and PTFE components are cocrystallized. We used PTFE with low $M_{\mathrm{n}}$ of about $1 \times 10^{5}$. This PTFE was a little brittle but made possible blending with FEP or PFA by a Brabender extruder. The blends obtained were not brittle and produced good sheets by 
compression molding, as with FEP and PFA. We believe that the low $M_{\mathrm{n}}$ PTFE used and the results are representative of crystallization behavior for the binary blends of PTFE having a large molecular weight with FEP and PFA.

Acknowledgment. The authors thank Prof. K. Moriya of Gifu University, Gifu, Japan for kind encouragement and valuable advice, and also Prof. K. Tadano of Gifu College of Medical Technology, Seki, Japan for useful discussion. The authors appreciate Mr. Y. Nishino for the experimental assistance and discussion. S. Y. is deeply indebted to Science and Technology Corporation, and Gifu Research and Development Foundation for their financial support. M. E. thanks Kai industries Corporation Ltd., Japan for the opportunity for the present investigations.

\section{REFERENCES}

1. J. Scheirs, "Modern Fluoropolymers," Wiley, New York, N.Y., 1997, chapt. 1.

2. L. A. Utracki, "Polymer Alloys and Blends: Thermodynamics and Rheology," Carl Hanser Verlag, Munich, 1989.

3. J. Runt, L. Jin, S. Talibuddin, and C. R. Davis, Macromolecules, 28, 2781 (1995).

4. R. Pucciariello and C. Angioletti, J. Polym. Sci., Part B: Polym. Phys., 37, 679 (1999).

5. R. Pucciariello, V. Villani, and O. Ruiz de Ballesteros, Macromolecules, 34, 1764 (2001).

6. M. Endo, K. Yamada, K. Tadano, Y. Nishino, and S. Yano, Macromol. Rapid Commun., 21, 396 (2000).

7. T. Noguchi and K. Ishiwari, Polym. Prepr. Jpn., 37, 2752 (1988).
8. C. W. Bunn and E. R. Howells, Nature, 174, 549 (1954).

9. S. Wu, Polym. Eng. Sci., 28, 538 (1988).

10. E. S. Clark, Bull. Am. Phys. Soc., 18, 3317 (1962).

11. J. J. Weeks, I. C. Sanchez, R. K. Eby, and C. I. Poser, Polymer, 21, 325 (1985).

12. S.-F. Lau, H. Suzuki, and B. Wunderlich, J. Polym. Sci., Polym. Phys. Ed., 22, 379 (1984).

13. M. Endo et al., unpublished data.

14. J. J. Weeks, R. K. Eby, and E. S. Clark, Polymer, 22, 1496 (1981).

15. A. Marigo, C. Marega, R. Zannetti, and G. Ajroldi, Macromolecules, 29, 2197 (1996).

16. S. V. Kostromina, N. V. Kozlova, Yu. A. Zybov, S. N. Chvalun, Ye. A. Fedorovich, and G. A. Ryvkin, Vysokomol. Soedin., Ser. A, 28, 886 (1986).

17. S. Minami, "Processing of Wave Signals for Scientific Measurements (in Japanese)," CQ Press, Tokyo, 1986.

18. W. C. Davidon, AEC Research and Development Report, ANL-5990 (1959).

19. R. Fletcher and M. J. D. Powell, Comput. J., 6, 163 (1963).

20. R. Pucciariello, J. Polym. Sci., Part B: Polym. Phys., 34, 1751 (1996).

21. V. Villani, R. Pucciariello, and R. Fusco, Colloid Polym. Sci., 269, 477 (1991).

22. A. M. Kronfeld, B. M. Tarakanov, A. V. Bezprozvannykh, and N. N. Loginova, Vysokomol. Soedin., Ser. B, 28, 446 (1986).

23. K. L. Hoy, J. Paint Technol., 42, 76 (1970).

24. S.-F. Lau, J. P. Wesson, and B. Wunderlich, Macromolecules, 17, 1102 (1984).

25. N. G. McCrum, B. E. Read, and G. Williams, "Anelastic and Dielectric Effects in Polymeric Solids," Wiley, New York, N.Y., 1967.

26. N. Koizumi, S. Yano, and F. Tsuji, J. Macromol. Sci., Part C: Rev. Macromol. Chem. Phys., 23, 499 (1968). 